\title{
Modernismo e identidade nacional: algumas considerações
}

\author{
HÉLIO R. S. SILVA*
}

Resumo: As pertinentes críticas ao sentimento de desterro no próprio Brasil, produzidas pelos modernistas a partir da década de 1920, terminaram por enrijecer demais a noção de brasilidade, ignorando a pluralidade cultural do país. A irreverência modernista institucionalizada servia de incentivo a um certo blaseismo, entronizado como marca da modernidade, obscurecendo a inevitável solenidade dos pactos sociais.

Abstract: Since the beginning of the $20^{\text {th }}$ century, relevant critics pronounced by modernists about the feeling of banishment in Brazil, ended tightening up the notion of Brazilian identity, ignoring the cultural plurality of the country. The institutional irreverence of the modernists, stimulated a certain blasé attitude, exalted as label of modernity, obscuring an inevitable solemnity of the social pacts.

Palavras-chave: Modernismo. Identidade nacional. Brasilidade.

Key words: Modernism. National identity. Brazility.

"[...] este jornal, ao nascer, dá prova de
uma coragem digna do Anhangüera:
destina-se a um público que não existe"
(editorial de Terra Roxa e Outras Terras,
20 jan. 1926).

Variáveis, fenômenos, processos, mudanças distintos e heterogêneos marcam as duas últimas décadas do século XIX e as duas primeiras do século XX no Brasil. Fatos históricos, transições institucionais, processos sociais, industriais, urbanísticos criam o que Richard Morse denominou há uns vinte anos de geração sem mar-

* Etnógrafo; professor da Faculdade de Filosofia e Ciências Humanas da PUCRS, Porto Alegre, Brasil. Mestre e Doutor pela Universidade Federal do Rio de Janeiro. 
co de referência. ${ }^{1}$ Em tal contexto são notórias as dificuldades que essa sociedade revela com a mudança e a transformação. A diferença e pluralidade nacional vistas, de certa forma, como ameaça, desagregação.

Enfim, vejamos propositalmente misturados fatores de renovação e fenômenos sintomáticos. Concentradas alterações em várias séries e múltiplos planos. A Abolição da Escravidão em 1888, a Proclamação da República em 1889, o processo imigratório - que traz ao país o equivalente a $1 / 4$ de sua população ${ }^{2}$ de nacionais de diversos países -, o impacto da Primeira Guerra Mundial, o surpreendente ritmo de industrialização e urbanização de São Paulo, as crises da República Velha, o surgimento de um operariado organizado, a progressiva "emancipação" feminina das redutoras redes domésticas, o telégrafo, o rádio, o cinema, o aeroplano, o impacto na consciência nacional dos episódios de Canudos, Contestado, Juazeiro e do fenômeno do cangaceirismo indicam o surgimento de uma nova sociedade e os espasmos da sociedade velha. O rol propositadamente tumultuado acima nos lembra que as mudanças históricas não nos atingem analiticamente. Chegam de cambulhada. Não produzem efeitos seqüenciais e lineares, se confundem e se entremodificam. Por outro lado, só ironicamente podemos hoje confrontar os fenômenos acima como a disputa entre o velho e o novo. Referimo-nos, no entanto, a um dos modelos de análise legados pelo modernismo às suas camadas escolarizadas: o Brasil, didaticamente, dual, o que pode ser representado, e não exclusivamente na metáfora cronológica do velho e do novo. Acreditamos antes que essas "assombrações" (para usar a expressão de Gilberto Freyre) são antes manifestações de alteridades não codificadas, como o sertão cearense pareceu também ao mais oficial dos escola-novistas, Lourenço Filho.

Latente e difuso sentimento de pasmaceira, de déja vu, impregna os primeiros anos do século, clima intelectual sob o qual séries distintas sofriam lenta erosão, deterioração, vagas e subterrâneas. Impronunciadas e mal pronunciadas, mal percebidas ou imperceptíveis mudanças em múltiplos planos que - súbito - em 1922 (sintomático, sismográfico) irrompem em formas públicas, manifestações e manifestos, ganhando contornos institucionais, precisos, reivindicativos, férteis em balanços e projetos (os 18 do

Morse, Richard M. "A economia de Manchester e a sociologia paulista". Dados, IUPERJ: Rio de Janeiro, n. 18, p. 33-56, 1978.

2 Se tomarmos como base a população brasileira em 1922. 
Forte, Centro D. Vital, o Partido Comunista Brasileiro e a Semana de Arte Moderna). ${ }^{3}$

O processo modernista, iniciado com a Semana, está fortemente marcado pelo espírito de "descoberta" do Brasil. Sem marcos de referência, a geração que a faz e desdobra em um processo intenso que sob o signo do escândalo e da polêmica irá agitar os meios culturais nas duas décadas seguintes, reflui ao marco zero, cabralinos e programaticamente inclinados a perceber tudo com olhos novos. Dissemina-se a idéia segundo a qual o século XIX teria experimentado uma europeização de estufa que abafara e subestimara as raízes populares de "nossa" cultura, que já dera, no século XVIII, mostras exuberantes de sua vitalidade no barroco mineiro.

Os modelos que presidiram essa empreitada descobridora colocam em circuito verdadeiros "Cabrais" do século XX que, debruçando-se sobretudo sobre a experiência colonial, dela retiram um fado, um destino, fatalidades essenciais que parecem obliterar a continentalidade brasileira, sua pluralidade cultural e a evidência de que o país entrava, exatamente pela amplitude das séries alteradas - e acima parcialmente listadas - em uma espécie de nova "nebulosa" da qual sairia reconfigurado para além da imaginação modernista e de sua capacidade intuitiva de dominar inteiramente a terra a descobrir.

O modernismo revela e dramatiza as dificuldades das elites brasileiras em lidar com a mudança e a diferença. A transformação e a alteridade parecem fantasmas, aparições perturbadoras do bom-senso hierarquizante e da superstição imobilista. A pluralidade nacional sempre foi vista como ameaça e desagregação.

Os inúmeros grupos formados pelas dissensões modernistas correspondem a particulares posições políticas, a específicos credos estéticos, mas há uma fronteira extremamente minada a sepa$\mathrm{rar} / \mathrm{unir} /$ confundir os dois grandes objetivos de todo o processo: descobrir e modernizar. Questão que remete aos clássicos problemas dos estudiosos de processos socioculturais: influência, contato, identidade cultural, mudança, tradição. E que alimenta curio-

É o caso, também, do "Grupo Teatro Social, dos anarquistas, fundado em São Paulo em 1922, ano da Semana de Arte Moderna". "Alguns ainda procuravam chocar a burguesia, outros cortejavam os desprotegidos, outros criavam mundos particulares de simbolismo. Havia crescente intercâmbio com outras regiões culturais do Brasil, e influência mútua entre as artes e as disciplinas de pesquisa. Para muitas pessoas o modernismo tornou-se antropologia social; recuperação do folclore abandonado; estudo das instituições sociais econômicas e políticas do Brasil; etnologia e filologia; história intelectual; ou crítica literária" (Morse, loc. cit., p. 346). 
samente o interminável e ocioso debate presente nas Histórias do modernismo, visto por uns como destrutivo, por outros como construtivo e por terceiros como tendo um momento destrutivo ao qual se seguiria uma momento construtivo.

Daí as tensas relações entre tais termos. Alguns grupos modernistas centram-se nas tradições e minimizam e/ou temem os processos de mudança. Outros grupos se alvoroçam com as postuladas benesses da moderna sociedade industrial e reduzem as tradições a seus aspectos (óbvios, mas não exclusivos) castradores. O duplo objetivo modernista (descobrir e modernizar o Brasil) contém uma tensão em termos. Não obstante, ambas as vertentes apesar de todas as diatribes, insultos e discrepâncias que as separam - ocupam o solo comum da descoberta de um ponto de vista cabralino. A ética da descoberta baliza o levantamento de valores e realizações que teriam sido subestimadas pela utópica pretensão de permanecer europeus nas Américas, mas infunde ânimo aos visionários extasiados com as perspectivas abertas pela indústria, pela tecnologia, pela metrópole. ${ }^{4}$

Acrescente-se aos traços levantados e às circunstâncias descritas que o Brasil dos modernistas era um Brasil até cartográfica e fisiograficamente desconhecido. Os mapas do Barão Homem de Mello então compulsados revelavam grandes claros inexplorados. Datam dessa época as explorações de Rondon e outros a inúmeras regiões brasileiras jamais pisadas por membros da sociedade nacional. E era ainda um Brasil de difíceis comunicações, em termos de correios, telégrafos e telefonia. Os deslocamentos dependiam em muito ainda da navegação de cabotagem, amparada aqui e ali pelas incursões das estradas de ferro a escoar o açúcar, o café, o cacau.

O lema do governo Washington Luís (1926-1930) tipifica muito bem o quanto isso era problemático, política e economicamente. "Governar é abrir estradas", proclamava o condescendente protetor dos modernistas.

4 Vide o editorial da revista Klaxon: "Era dos 8 batutas, do Jazz-Band, de Chicharrão, de Carlito, de Mutt \& Jeff. Era do riso e da sinceridade. Era de construção. Era de Klaxon". Vide os títulos de obras modernistas: "O Domingo dos Séculos", "Paulicéia desvairada", "Libertinagem"...

5 Sobre a relação entre Washington Luís e os modernistas, ver PICCHIA, Menotti del. A Longa Viagem - 2" etapa: da revolução modernista à revolução de 1930. São Paulo: Martins/Conselho Estadual de Cultura, 1972. Um exemplo concreto das dificuldades que cercavam uma viagem no Brasil de então encontra-se em relato pormenorizado de uma viagem às cidades históricas de Minas, empreendida por um grupo moder- 
Era ainda o país sem universidade e sem tradição de pesquisa. Portanto, um vasto território a ser estudado. Os modernistas preferiram defini-lo.

"Reveladores" de um Brasil que realmente não conheciam, vão criando, em função de interesses, posições estéticas, políticas, de suas próprias imaginações, um Brasil projetivo, cujos conteúdos informam mais sobre seus formuladores do que realmente sobre o vasto território circunscrito pelos limites de um Estado Nacional, a abrigar inúmeras sociedades, de vária procedência e com projetos distintos.

Descobrir o país tinha o mesmo sentido da metáfora emprestada por Mário de Andrade à poesia em "A escrava que não é Isaura". Tratava-se de despojá-la de vestes, adornos, ornamentos, expletivos e acessórios. Isto é, tocar no essencial.

Viver a modernização consistia muitas vezes em se lançar numa experiência embriagadora, ${ }^{6}$ ou atemorizante. ${ }^{7}$

Vejamos três séries de expressões, imagens ou metáforas de grande freqüência nos textos modernistas. A primeira, quanto ao próprio processo: período de descobertas inaugurais, descobrimento, madrugada, país dos meninos e poetas, marco zero, cabralismo, palmilhação dos climas, houvemos vista de terra, primeiro caderno do alumno de poesia. ${ }^{8}$ A segunda, quanto à organização de sua visão das coisas: síntese, clareza, raiz, equilibrio geômetra, essencial, acabamento técnico, primitivo e primitividade, economia verbal. Ao que se acrescenta a preocupação com a limpidez visual, expressa pela preocupação acentuada com o design e a diagramação. A terceira, exprimindo a ética dos novos tempos: extirpação das glândulas lacrimais, alegria éa prova dos nove, surpresa, espontaneidade. A atenção com que cercam

nista (In: AMARAL, Aracy. Blaise Cendrars no Brasil e os modernistas. São Paulo: Martins, 1970).

" "Todo esse tempo destruidor do movimento modernista foi pra nós tempo de festa, de cultivo imoderado do prazer. E si tamanha festança diminuiu por certo nossa capacidade de produção e serenidade criadora, ninguém pode imaginar como nos divertimos" (ANDRADE, Mário de. Aspectos da literatura brasileira. São Paulo: Martins, 1978).

Como é o caso exemplificado na advertência de Plínio Salgado para que os integralistas evitassem cinemas e confeitarias, loci corruptores da nacionalidade. Referimonos ao integralismo (Ação em oposição à Nhengaçu, ou discurso) como um dos desdobramentos do grupo verde-amarelo, politização da vertente autoritária, incrustrada no modernismo.

8 Haroldo de Campos percebe na obra de Oswald de Andrade "uma poética da radicalidade" (Campos, Haroldo de. "Uma poética da radicalidade". In: Andrade, Oswald de. Poesias reunidas. São Paulo: Difel, 1966). 
Piolin exprime ao mesmo tempo esse estado de graça e a tendência popular do movimento.

Postas de lado as questões exclusivamente e tecnicamente estéticas, o que interessa aqui é o quanto o exercício desse discurso não faz transbordar predisposições e valores para o âmbito do conhecimento e da ética da nacionalidade. Uma alegre ética da elementaridade inaugural, um Brasil diagramado e claro. Essas imagens reiteradas elaboram uma ética de pertencimento ao país e uma visão de sua engenharia relacional regidas pelas idéias de começo, essencialidade, espontaneidade e alegria.

No ensaismo modernista, a experiência de começo (colonial) essencializa (o homem cordial, o brasileiro triste, sem preconceitos, malandro) e a questão moral se facilita na busca da autenticidade, que não é assumida como um processo trabalhoso de construção do sujeito moral, mas como um se soltar, um se largar, em nome da espontaneidade e da alegria que alter me rouba. (Isso cria uma ética da responsabilidade para comigo em substituição à única regra possível de convivência social, a responsabilidade para com o outro). É claro que explicitamente o ladrão da alegria é o colonizador que nos trouxe a idéia de pecado e de inferno, a morbidez romântica, a tuberculose, as doenças de pele e dos brônquios. Essa primitiva ética do desrecalcamento e da espontaneidade (fundada como símbolo de convivência em um continente de múltiplas sociedades forçadas ao convívio nacional e integradas em um Estado) inicia-se com o mito de que o repressor está na Europa e é nosso antípoda. Isso se deve ao fato de que nossas características são encontradas reativamente em todos aqueles traços que nos contrastam (nu/vestido, patriarcalismo/matriarcado, morbidez/saúde, tristeza/alegria, comportamento regulamentado/comportamento espontâneo), mas só podem alimentar-se realmente dos atritos cotidianos de nossa inamistosa convivência com a alteridade que integra um projeto dado como miscigenado e sincrético - e, portanto, integrante também dessa brasilidade postulada como homogênea.

- Ou "A poesia 'pau-brasil' é o ovo de Colombo - esse ovo, como dizia um inventor meu amigo, em que ninguém acreditava e acabou enriquecendo o genovês. Oswald de Andrade, numa viagem a Paris, do alto de um atelier da Place Clichy - umbigo do mundo - descobriu, deslumbrado, a sua própria terra. A volta à pátria confirmou, no encantamento das descobertas manuelinas, a revelação surpreendente de que o Brasil existia. Esse fato, de que alguns já desconfiavam, abriu seus olhos à visão radiosa de um mundo novo, inexplorado e misterioso. Estava criada a poesia "pau-brasil"” (Prado, Paulo. "Poesia Pau Brasil". In: Andrade, Oswald de. Poesias reunidas. São Paulo: Difusão Européia do Livro, 1966). 
É por isso que ante os mais alarmantes impasses e problemas criados por diferenças de códigos e de valores, a professora da escola rural tradicional, formada por Dr. Lourenço Filho e seguidores, somente acionava um repertório psicológico ${ }^{10}$ à maneira do criador do INEP, quando no Ceará. Se são formas mentais e públicas para se pensar relações entre diferentes, tudo que me escapa, ou é a "assombração" de Gilberto Freyre ou a patologia do nosso primeiro catedrático em Psicologia.

De qualquer maneira, os diagnósticos modernistas, apesar de suas diferenças, contêm algumas regularidades sintomáticas. Nas tentativas textuais de conciliar o duplo objetivo, modernizar e encontrar a identidade, buscam imagens inaugurais, ${ }^{11}$ signos elementares, logotipos, a poesia concreta de Oswald, a idéia de despojamento. Essas imagens nuas essencializam a visão de Brasil. A praia, a claridade, o desbravador de mares, o índio nu. Metáforas de claridade, manhã, primitividade, inaugurais. Em síntese, a_experiência de espanto, para usar a bela imagem cunhada pela Dra. Ruth Gauer, analisando a expansão marítima e os descobrimentos portugueses. Toda estratégia modernista nos combates a que se entrega e nos quais se empenha ao longo do processo de embates e polêmicas nas décadas seguintes à semana consistiu em uma permanente tentativa de desbastamento da retórica do século XIX, dos ornamentos da linguagem pedante do bacharel, do deputado, do orador de festinhas domésticas. ${ }^{12}$ A grandiloqüência da estatuária. ${ }^{13}$

Há no modernismo a tematização de uma grandeza perdida, mas sobretudo a repulsa a uma sub-espécie de grandeza que se degrada na corrupção. Seu antilusitanismo (e anti-francesismo) ${ }^{14}$ tão tematizado nos compêndios e nas sínteses apressadas (que deixam de perceber que o alvo é um certo emplastramento cortesão que teve seu período de maior visibilidade - para nós brasileiros - entre 1808 e 1889).

10 Referência à pesquisa realizada pelo autor no âmbito do Instituto de Estudos Avançados em Educação da Fundação Getúlio Vargas.

"Imagens cuja expressão máxima está contida na divisa atribuída à Escola de Sagres: "navegar é preciso, viver não é preciso". Na sabedoria que circunavega a navegação portuguesa.

12 Outras expressões foram encontradas para designar a prática retórica à qual nos referimos: "Os mitos do bem dizer" (Mário da Silva Brito); "patriotismo ornamental" (Antônio Cândido): "retórica tribunícia" (Haroldo de Campos).

13 "A contribuição milionária de todos os erros: como falamos, como somos"; "Alegria dos que não sabem e descobrem"; "Contra o gabinetismo, a prática culta da vida"; "Contra o detalhe naturalista". 
O espírito cabralino fornece imagens de traços econômicos: a casca da nau, a bússola, a linha de praia, a índia nua. Diálogos inaugurais, as perguntas de começo, o começo de uma conversa. $\mathrm{Na}$ operação de desbastamento dos resíduos e arabescos tidos como excrescentes pelos modernistas, estes terminam quase sempre a refluir para aquela praia paradisíaca, topografia da promessa e da esperança.

Depois, vieram os donatários. Ou nem vieram. ${ }^{14}$

Mas, qual a fonte deste dístico notável e consagrado pela reverência de todas as vanguardas e dos autores mais ousados e insubmissos: "Pelos roteiros. Acreditar nos sinais, acreditar nos instrumentos e nas estrelas"? É claro, o espírito cabralino.

Assim também entre os verde-amarelos, opositores do paubrasil e da antropofagia, antípodas das idéias de Oswald. Todo o Brasil vincula-se simbólica e relacionalmente ao encontro primeiro do tupi com o português. Experiência que liquida com o jacobinismo, o isolamento e a desagregação.

Gilberto Freyre desentranha a plasticidade portuguesa de suas próprias origens antropológicas em seu sentido físico, da geografia, posição intermédia de Portugal, da experiência históri$\mathrm{ca}$, as invasões sofridas e contatos estabelecidos na Península Ibérica, e ainda da intensa miscigenação que marcou toda sua história, antes e depois da expansão marítima. Quase um fado, a nos trazer na figura do ator básico de nossa formação esse antitraço tão caro a todos os modernistas: a ambigüidade. $O$ nacionalismo dos portugueses nutre-se de ódio ao mouro e, posteriormente, ao espanhol. São para o autor ódios criadores que atuam sobre seu caráter.

A própria casa-grande de engenho lança sua pedra fundamental no solar português, de taipa ou de barro amassado, desde então uma unidade econômica. A política colonial vai tecendo

14 "O lado doutor. O bacharel". "O império foi assim. Eruditamos tudo. Esquecemos o gavião de penacho". "Contra todas as catequeses". "Contra o Padre Vieira. Autor do nosso primeiro empréstimo para ganhar comissão. O rei analfabeto dissera-lhe: ponha isso no papel, mas sem muita lábia. Faz-se o empréstimo. Gravou-se o açúcar brasileiro. Vieira deixou o dinheiro em Portugal e nos trouxe a lábia". "Contra Goethe, a mãe dos Gracos e a Corte de D. João VI". "A nossa independência ainda não foi proclamada. Frase típica de D. João VI: - 'Meu filho, põe esta coroa na tua cabeça antes que algum aventureiro o faça!' Expulsamos a dinastia. É preciso expulsar o espírito bragantino, as ordenações e o rapé de Maria da Fonte" ("Manifesto Antropófago". Revista de Antropofagia; reedição da Revista Literária publicada em São Paulo$1^{\underline{a}}$ e $2^{\mathrm{a}}$ "dentições" - 1928-1929. São Paulo, 1976. "Manifesto da Poesia Pau-Brasil". In: TELES, Gilberto Mendonça. Vanguarda européia e Modernismo Brasileiro; apresentação e crítica dos principais manifestos vanguardistas. Petrópolis/Brasília: Vozes/INL, 1976). 
grandioso destino da região, deslocando "indivíduos de valor, guerreiros, administradores, técnicos [...] como peças num tabuleiro de gamão: da Ásia para a América ou daí para a África, conforme conveniências de momento ou de religião. A Duarte Coelho, enriquecido pela experiência da Índia, entrega a D. João III a nova capitania de Pernambuco....". ${ }^{15}$ O Brasil se elabora: "Mudado em São Vicente e em Pernambuco o rumo da colonização portuguesa do fácil, mercantil, para o agrícola". ${ }^{16}$

$\mathrm{Na}$ fase colonizadora, fim do século XVI parte do XVII, o Brasil ganha expressão entre as nações, graças à valorização do açúcar. ${ }^{77}$ Introduzido por árabes e mouros na Península, e transportado da Ilha da Madeira para o Brasil, torna-se assim a condicionante do nosso desenvolvimento econômico e social. ${ }^{18}$

Como em quase todo ensaísmo modernista, há uma certa unção no tom com que se descreve os primeiros tempos, que imprimem o sinete de uma condição. A experiência primeira para Gilberto Freyre é a fundação da sociedade em Pernambuco. "[...] as grandes plantações foram obra... de corajosa iniciativa particular. Esta é que nos trouxe pela mão de um Martim Afonso, ao sul, e principalmente de um Duarte Coelho, ao norte, os primeiros colonos sólidos, as primeiras mães de família, as primeiras sementes, o primeiro gado, os primeiros animais de transporte, plantas alimentares, instrumentos agrícolas, mecânicos judeus para as fábricas de açúcar, escravos africanos para o trabalho de eito e de bagaceira...".

A célula mater da nacionalidade não é o negro, o índio, o bandeirante, o patriarca. Há um líder, um founding father, Duarte Coelho, mas o que esse herói civilizador planta é uma sociedade. A unidade mínima com que Freyre pensạ o Brasil já instaura o princípio do social. Ela pressupõe a matização interna dos atores sociais enumerados, a complexidade às trocas e, ainda, as coisas a serem trocadas. Colonos, mulheres, mecânicos judeus, escravos africanos. Gado, animais de transporte. Instrumentos agrícolas. Sementes, plantas alimentares. Justapostos na cadeia sintagmática, cujos elos se ligam pela solda da palavra primeira, mães e sementes.

15 Freyre, Gilberto. Casa Grande E Senzala (Coleção Biblioteca Básica Brasileira, $\mathrm{n}^{\mathrm{a}} 7,12^{\mathrm{a}}$ edição brasileira, $13^{\mathrm{a}} \mathrm{em}$ língua portuguesa). Brasília: Editora Universidade de Brasília, 1963, p. 73.

16 Idem, p. 69.

17 Idem, p. 254.

18 Idem, p. 266.

$19 \quad$ Idem, p. 82. 
Quanto a Sérgio Buarque de Hollanda, sua interpretação assegura, como todas as outras interpretações modernistas, papel privilegiado à colonização. A civilização brasileira teria sido um produto da civilização portuguesa, ou melhor, uma extensão desta, com pequenas dessemelhanças produzidas pelas vicissitudes de sua implantação e aclimatação. Essa civilização deriva de uma região de transição, a Península Ibérica, onde o europeísmo não é tão fortemente marcante.

O rompimento com a vida da corte, a aristocratização das elites brasileiras, o francesismo que produz uma mentalidade reativa à Europa não transcende inteiramente a referência européia. Rompe com a Corte de D. João VI, a Missão Artística Francesa ${ }^{20}$, mas retoma fundo a vertente cabralina que se prolonga nos cronistas coloniais. O desbastamento dessa civilização julgada ociosa, perniciosa, fora do lugar se dá pelo exorcismo de um olhar inaugural que essa mesma civilização lega, outorga e legitima.

"Cabralismo", primeira palavra no manifesto que abre o livro-manifesto de Oswald de Andrade, precedido do contundente prefácio de Paulo Prado: "no encantamento das descobertas manuelinas".

Encantamento, revelação, deslumbramento, mundo novo, inexplorado e misterioso. Poderíamos dizer sobre os modernistas que a produção deste mistério foi tão programática quanto a navegação entre portugueses. "Olhar com olhos novos". Como antropólogo, permita-nos lembrar o truísmo: estranhar o familiar. Ora, a fonte que possibilita esse estranhamento, paradoxalmente, é lusitana. E é nesse exercício de estranhamento que o familiar irá se reconfigurando.

Raízes. Palavra de alta freqüência no período. Essência. Só que o mundo novo que se avizinha está a se produzir naquele momento. Indústria, urbanização, república, feminismo, desenho industrial, programação visual. Vislumbrado como um mundo sem arestas, sem ornamentos, funcional, diurno e público.

20 Estabelecer conexão com a observação feita pelo Dr. Afonso Carlos Marques dos Santos sobre a missão da Academia de Belas Artes: produzir o imaginário do Estado brasileiro e do processo civilizatório do Brasil.

O modernismo busca uma iconografia brasileira, uma língua brasileira ("a língua sem arcaismos, sem erudição. Natural e neológica", "a contribuição milionária de todos os erros", "como falamos, como somos" ("Manifesto da Poesia Pau-Brasil". In: Teles, Gilberto Mendonça. Vanguarda Européia e Modernismo Brasileiro; apresentação e crítica dos principais manifestos vanguardistas. Petrópolis/Brasília: Vozes/INL, 1976). Contra o purismo, a obsessão vernacular ("a gramatiquinha brasileira" de Mário de Andrade, "o ítalo paulista" de Antônio de Alcântara Machado). 
As imagens dos primeiros contatos: as onduladas ilhas de Tarsila, as claras e cinematográficas imagens de Caminha, o essencialismo da viagem e dos olhos rebatem-se sobre o imaginário que se produz no limiar desse mundo moderno.

As metáforas cabralinas no discurso conciliam a contradição ou a desestabilização entre as duas metas: descobrir-se e modernizar-se. A busca de uma essência colonial, despojadas dos atavios das desconversas de tudo que foge a essa radicalidade que estaria presente também na modernização.

Os modernistas convocam um imaginário e produzem imagens de notável eficácia formal e discursiva, restaurando uma unidade entre origem e destino, uma correspondência entre identidade e projeto, na medida mesma em que as múltiplas versões de criação do Brasil transformam a história em mito. O que se resgata do período colonial é um fado, um destino.

Isso não implica em deixar de reconhecer o quanto obras como as de Sérgio Buarque de Holanda ou Paulo Prado estão a apontar os entraves à modernidade, à modernização, à constituição de um pleno projeto público no Brasil, nas mazelas e seqüelas do passado. Mas, se bem vistos, seus alvos maiores são as instituições, hábitos, costumes e tendências esboçados e plenamente aflorados no século XIX.

A questão que emaranha a visão do futuro nos inícios do século consistia sobretudo em manter essa espécie de facho civilizacional, tornando o Brasil uma extensão da Europa, ou melhor, simplesmente assegurando a urgência e predomínio da civilização européia nos trópicos sob pena de regressão à barbárie.

"Sou heleno, ceuta e tapuia", dizia Euclides da Cunha. E, ante o grupo anárquico que arrebata em 1924, Graça Aranha da Academia Brasileira de Letras, como exprimindo o grito agônico de um náufrago, ou a frase solene do comandante que vê seu navio ir a pique, gritou Coelho Neto: "Sou o último dos Helenos".

Aristocracia que se vestia com Poiret, bebia água de Vichy e escrevia diários íntimos em francês.

Expurgadas as caricaturas contidas em algumas performances, as costuras dessas resistências perdidas, que apontavam para uma possibilidade de aprofundamento da experiência européia nos trópicos, hoje nos soam como uma possibilidade perdida, mas não amaldiçoável.

O legado modernista implicou num corte com o século XIX, que povoa a imaginação média nacional sob formas sombrias, personalidades caricatas, desprovidas de vínculos com o contexto, 
antivivendo a repressão de seus conteúdos e reprimindo suas formas.

O século XIX hoje no Brasil é matéria para especialista. A teia complexa que enreda o mundo institucional brasileiro tecido nos últimos 200 anos torna-se obscura, aviltando nosso sentimento de tradição e, portanto, de pertencimento.

As múltiplas versões de Brasil concebidas são sempre excludentes. Variam apenas quanto a quem está sendo excluído.

A irreverência modernista programática fez-nos perder um pouco o alto sentido social da ritualização, penhor do respeito ao próximo.

Entramos nesses complexos processos de mudanças sem as salvaguardas das tradições e dos elementos de continuidade. Nossas elites passaram a nos governar e indicar nossos rumos sob o signo do novo. Estado Novo, Brasília, Cruzado, Real, Educação Nova, Arte Moderna, Nova República. Assim nossas mais densas expressões culturais: Cinema Novo, Bossa Nova, Jovem Guarda.

O penhor do novo e da novidade talvez esteja na vitória sobre uma resistência da tradição. O Brasil tornou-se neste século novidadeiro, domingueiro e desmemoriado.

Todo o problema dos nacionalismos exacerbados consiste exatamente no esforço desesperado para fazer migrar o sentimento de pertencimento, que decorre da experiência social de viver em uma comunidade de pequena escala, para um sentimento que se imponha a uma experiência política de inserção como cidadão em uma rede expandida, rarefeita, muitas vezes continental, de coletividades distintas. Esforço este levado a cabo por discursos que produzem símbolos, signos e sinais monovalentes. Transmitem-se, migram sobre vastidões, pousando sobre distintos contextos culturais, que emprestam ou não emprestam signos provinciais para integrar o todo. Terminam por nos conferir um vago caráter que, de tão repetido, nos atribui um surplus, fantasia folgada e sobreposta aos costumes compartilhados nas afetivas e, portanto, efetivas interações face a face.

O nacional, para nós, passou a ser essa contraface inculcada. No momento em que o país agudizava a experiência de heterogeneidade e se complexificava num ritmo notável, o refluxo cabralino à praia primordial onde uma certa semente teria sido plantada para que os modernistas a decodificassem, associado ao repúdio cabal à continuidade produzida no século XIX, um tempo-chave para o Brasil em termos de ensaios institucionais, modelos políticos, atividade cultural e intelectual, minaram as boas intenções modernistas e perverteram o espírito de convivência, inamistoso 
às negociações inerentes ao plano social, sobretudo em um país de composição cultural tão exponencialmente heterogênea, esquecido das tessituras que o cotidiano tece e da imperativa necessidade de perceber que por menos edificante que tenha sido a nossa experiência oitocentista, suas injustiças, repressões e mediocridades não se expressaram sem tensões entre o possível e o desejável, entre o justo e o cumprido, entre direitos e suas supressões. A reverência acrítica ao passado imobiliza a cidadania e obscurece o entendimento das necessárias mudanças que reptos novos sempre impõem. A ideologia da ruptura e do começo pleno apaga, por outro lado, as pegadas múltiplas que nos indicam como chegamos aqui. Elas podem ser erráticas ou incertas, mas contêm a solenidade do que jamais poderá ser vivido de outro modo. Somos de certa forma responsáveis pelos erros de ancestrais, somos de certa forma sujeitos do passado e seus autores. Negar isso é ocultar que o outro é um possível de mim. O que termina por ocultar minhas responsabilidades e o cultivo do meu senso de discernimento. Se uma qualidade fatal me constitui, se um fado me tange, se uma essência foi plantada naquela praia inaugural que me inaugura, é certo pensar que todos os desacertos foram obra de um extravio condenável. Isso, uma vez comungado, nos divorcia de todos e estabelece um regime de comunhão fratricida e irresponsável, erigida em nome de minhas certezas inabaláveis. A diferença se torna assim uma maldição, um atentado, ou pior ainda, se torna risível, cafona, brega, nordestina, baiana, gaúcha, alagoana, piauiense, folclórica, terminologia com a qual criamos os estereótipos que transitam no continuum entre o deboche e o extermínio.

De certa forma - e sem com isso pretender o obscurantismo de anatematizar a produção estética notável e relevante dos modernistas, nosso patrimônio - os libertários imbuídos de um fantástico sentimento de missão e com as melhores intenções, concorreram, pelo aproveitamento acrítico e diluído de seu acervo, para um regime de libertinagem preconceituosa, que nos untou com a pasta indiscriminada das mais suspeitas fusões, gerando um saldo de ressentimentos que corroeu todas as referências e entronizou o blaseísmo plebeu do garçom de costeletas a que se referiu Oswald na década de 1940, ante o monstro que involuntariamente criara. 